\title{
Review
}

\section{Mechanisms of synaptic depression triggered by metabotropic glutamate receptors}

\author{
C. Bellone ${ }^{\mathrm{a}}$, C. Lüscher ${ }^{\mathrm{a}, \mathrm{b}, *}$ and M. Mameli ${ }^{\mathrm{a}}$ \\ ${ }^{a}$ Dept. of Basic Neurosciences, Medical Faculty, University of Geneva, 1211 Geneva (Switzerland), \\ Fax:+41 2237954 52, e-mail: Christian.luscher@unige.ch \\ ${ }^{\mathrm{b}}$ Clinic of Neurology, Dept. of Clinical Neurosciences, Geneva University Hospital, 1211 Geneva (Switzerland)
}

Received 13 May 2008; received after revision 07 July 2008; accepted 11 July 2008

Online First 19 August 2008

\begin{abstract}
Glutamate, by activation of metabotropic receptors (mGluRs), can lead to a reduction of synaptic efficacy at many synapses. These forms of synaptic plasticity are referred to as long-term depression (mGluR-LTD). We will distinguish between mGluR-LTD induced by pre- or postsynaptic recep-
\end{abstract}

tors and mGluR-LTD induced by the locus of the expression mechanism of the synaptic depression. We will also review recent evidence that mGluR-mediated responses themselves are subject to depression, which may constitute a form of metaplasticity.

Keywords. Long-term depression, synaptic transmission, metabotropic glutamate receptors, AMPA receptors.

\section{Introduction}

The molecular mechanisms underlying many forms of long-term synaptic changes - Long Term Depression (LTD) in particular - have been studied in detail at fast glutamatergic synapses [1-3]. Here, we focus on mGluR-LTD that initially has received less attention than N-methyl-D-aspartic acid (NMDA) receptordependent LTD [3], but is now the focus of great interest.

mGluRs are $G$ protein-coupled receptors that are divided into three groups (I through III), based on their sequence homology, transduction mechanisms and pharmacology $[4,5]$. Group I (Gp I) comprises mGluR1 and mGluR5 which are linked to G proteins of the Gq type. They activate phospholipase C (PLC) to form diacylglycerol (DAG) and inositol 1, 4, 5-tris phosphate (IP3) [4], and are primarily expressed at

* Corresponding author. postsynaptic sites. Group II (Gp II) receptors (mGluR2 and mGluR3) couple to Gi/o proteins, which inhibit cyclic adenosine 3'5'-monophosphate (cAMP) formation and calcium $\left(\mathrm{Ca}^{2+}\right)$ channels at pre- and postsynaptic sites, and activate G-proteincoupled inwardly rectifying $\mathrm{K}$ (GIRK) channels at postsynaptic sites [6, 7]. Group III (Gp III) mGluRs (mGluR4, mGluR6, mGluR7 and mGluR8) couple to Gi/o proteins inhibiting adenylyl cyclase and $\mathrm{Ca}^{2+}$ channels at presynaptic sites and thereby modulate neurotransmitter release [8].

mGluR-LTD has been observed after activation of mGluR1, mGluR5, mGluR2, mGluR3 and mGluR7. Here, we classify these different forms of synaptic depression according to the locus of induction and expression of plasticity. By induction we mean the signaling events that are required to initiate the plasticity, such as the activation of the receptors themselves, the depolarization of the postsynaptic neuron or the increase in $\mathrm{Ca}^{2+}$ levels. The expression mechanisms refer to the cellular events that are 
Table 1. Classification of distinct forms of mGluR-LTD. The loci of induction and expression are indicated as postsynaptic (post) or presynaptic (pre). For further discussion, see text.

\begin{tabular}{llllll}
\hline Different forms of mGluR-LTD & & & & \\
\hline Group & Receptor that triggers LTD & Locus of & & Brain region & Nomenclature used \\
\cline { 3 - 5 } & & Induction & Expression & & \\
\hline Gp I & mGluR1 & Post & Post & VTA, Cerebellum & mGluR1-LTD \\
& & Post & Pre & NAcc & eCB-LTD \\
& mGluR1/5 & Post & Post & Striatum & Hippocampus \\
& & & & Spinal cord & mGluR5-LTD \\
Gp II & mGluR2 & Pre & Pre & Mossy fibers & mGluR2 \\
& & Post & Post & Cortex, BNST & mGluR2 \\
& mGluR7 & Pre & Pre & Mossy fibers & mGluR7-LTD \\
Gp III & & & & &
\end{tabular}

directly responsible for the change in synaptic efficacy (e.g. change in transmitter release or change in number/sensitivity of receptors). We distinguish between six forms of mGluR-LTD (Table 1, Fig. 1), defined by receptor type, the locus (post- or presynaptic) of LTD induction and expression, and the brain region. We will review the literature for each form of mGluR-LTD, focusing on the underlying molecular mechanism and concluding with the description of the plasticity of the mGluR-mediated synaptic currents themselves.

\section{Presynaptic induction - presynaptic expression}

At many synapses, Gi/o-coupled receptors located at the terminal boutons (= presynaptic element) can regulate the efficacy of transmission. Presynaptic Gp II and Gp III mGluR autoreceptors on glutamatergic synapses can inhibit presynaptic voltage-dependent $\mathrm{Ca}^{2+}$ channels, which suppress the $\mathrm{Ca}^{2+}$ transient when the action potential invades the terminal, eventually reducing transmitter release $[9,10]$. The two groups show distinct ultrastructural expression patterns; Gp II mGluRs are evenly distributed at the terminal [11, 12], while group III mGluRs are concentrated at presynaptic active zones $[13,14]$. Gp III mGluRs have a lower affinity for glutamate than the Gp II mGluRs and thus they require higher glutamate concentrations for their activation.

Presynaptic mGluR-LTD can be observed at hippocampal mossy fiber synapses, which arise from granule cells in the dentate gyrus and connect to CA3 pyramidal cells as well as stratum lucidum interneurons. While inputs onto pyramidal cells are formed by large presynaptic boutons, synapses onto stratum lucidum interneurons consist of small varicosities [15]. The former express mGluR2, the latter
mGluR7 [12] and as a consequence, mGluR-LTD of these two synapses show contrasting properties.

In CA3 neurons, synaptic depression requires both a presynaptic mGluR2-dependent decrease in cAMP and a rise of $\mathrm{Ca}^{2+}$ in the terminal [16]. mGluR activation occurs during high-frequency activity or with single shocks when glutamate uptake is blocked. mGluRs rapidly inhibit transmitter release [17, 18], which can become long-lasting. The involvement of mGluR2 is demonstrated by the observation that mGluR-LTD in mGluR2 knock-out (KO) mice is almost abolished [19, 20].

In stratum lucidum interneurons, the depression is induced by mGluR7. Because of its low affinity for glutamate, LTD induction at this synapse requires intense presynaptic stimulation. Interestingly, once LTD is induced, for example with an mGluR7 agonist or high frequency stimulation protocol, subsequent activation of the same receptors can lead to potentiation [21]. Moreover, the induction requirement is different early during postnatal development when mGluR7 has a higher affinity for glutamate [22].

The expression mechanism of these entirely presynaptic forms of mGluR-LTD is not well understood, but may share overlapping mechanisms with the endocannabinoid-mediated LTD (eCB-LTD, see below). Possible scenarios for the switch to a permanent depression after sustained Gi/o activation involve molecules that regulate presynaptic inhibition of mGluRs such as protein kinases [2325]. It has been suggested that mGluR7-LTD depends on protein kinase C (PKC), while mGluR2LTD would be modulated by the cAMP-protein kinase (PKA) pathway [16]. In line with this, cAMPdependent PKA inhibits the function of Gp II mGluRs at excitatory synapses in CA3 of the hippocampus and at medial perforate path-dentate gyrus synapses [26]. 
A

mGluR1-LTD

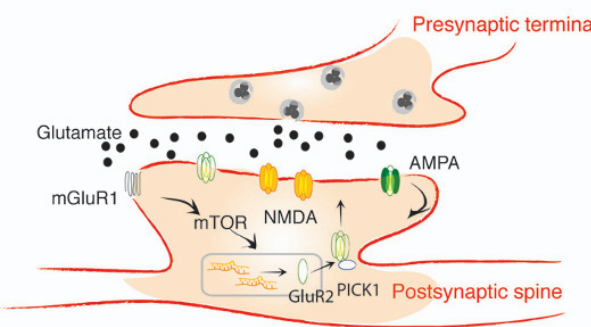

C

eCB-LTD

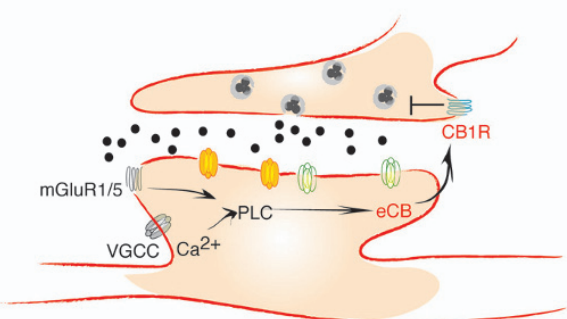

B

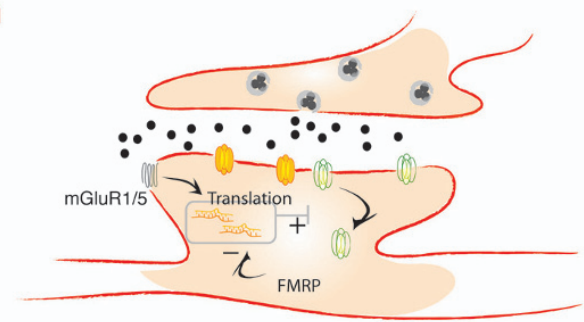

D

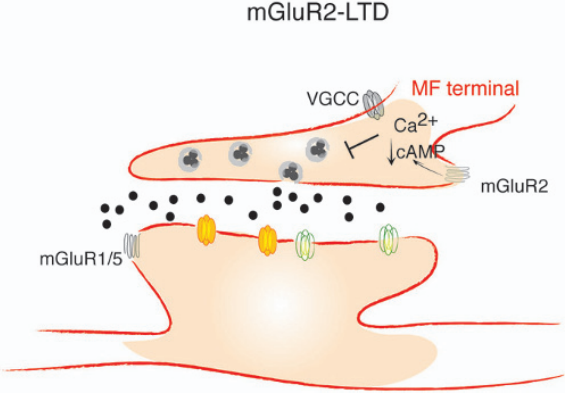

Figure 1. Models of some forms of mGluR-LTDs. (A) mGluR1- LTD in the ventral tegmental area requires mTOR and the de novo synthesis of GluR2. GluR2-containing low conductive AMPAR are then inserted at the synapse in exchange for GluR2-lacking high conductive AMPARs. $(B)$ mGluR1/5-LTD in the hippocampus also requires the activation of the protein synthesis machinery, however it remains elusive which proteins need to be synthesized. (C) eCB-LTD has been described at many synapses in several regions of the central nervous system. It requires the activation of Gp I mGluRs and PLC leading to intracellular $\mathrm{Ca}^{2+}$ rise that triggers the synthesis of eCB in the postsynaptic neuron. The eCBs are then released from the postsynaptic terminal and diffuse retrogradely to the presynaptic terminal, where they bind to CB1Rs, causing a reduction of neurotransmitter release. (D) Purely presynaptic mGluR2-LTD has been observed at mossy fiber to CA3 synapses of the hippocampus. Presynaptic activation of mGluR2 leads to the inhibition of adenylyl cyclase activity, reducing the levels of cAMP. Concomitant rise of $\mathrm{Ca}^{2+}$ and mGluR2 activation permanently reduces the release probability. Abbreviations: AMPA, alpha-amino-3-hydroxy-5-methyl-4-isoxazolepropionic acid; cAMP, cyclic adenosine monophosphate; CB1, cannabinoid receptor type 1; eCB, endocannabinoid; NMDA, N-methyl-D-aspartic acid; mTOR, mammalian target of rapamycin; FMRP, fragile X mental retardation protein; PLC, phospolipase C; VGCC, voltage-gated calcium channel; PICK1, protein-interacting C Kinase 1.

Taken together, Gp II and III mGluRs act as autoreceptors in the hippocampus and several other synapses of the brain $[10,27-30]$. Their activation by strong and sustained release of glutamate induces a permanent change in release probability that mediates this presynaptic form of LTD.

\section{Postsynaptic induction - postsynaptic expression}

\section{Postsynaptic Gp I receptors}

Gp I mGluRs are expressed postsynaptically and can trigger LTD in several areas of the brain such as hippocampus, cerebellum, ventral tegmental area (VTA) and bed nucleus of stria terminalis (BNST) [31-35]. Because Gp I mGluRs are located outside of the postsynaptic density $[36,37]$, they are activated when glutamate spills out of the cleft. Adequate protocols that will induce LTD therefore require sustained high frequency trains of up to $300 \mathrm{~Hz}$ [38], burst-like firing of several short trains at $66 \mathrm{~Hz}[32,33$, 39] or paired-pulse low frequency stimulation [40]. Alternatively, low frequency stimulation paired with the depolarization of the postsynaptic neuron [41-43] also seems to activate these receptors. However, even with strong induction protocols, only a fraction of synapses express LTD. Chemical induction with mGluR agonists such as dihydroxyphenylglycine (DHPG) have therefore been very useful for the investigation of the underlying mechanisms [31, 4446]. Since such chemical LTD occludes the efficacy of subsequent synaptic LTD, it is assumed that both forms share the underlying mechanism [31, 39].

The use of $\mathrm{KO}$ mice to determine the relative involvement of the mGluR1 and mGluR5 in mGluR-LTD has been difficult. The mGluR-LTD in the CA1 region of the hippocampus is absent in $\mathrm{mGluR5^{-/ }}$ mice, but also reduced in $\mathrm{mGluR} 1^{-/-}$mice $[40,47]$. Moreover, in wildtype mice, only the combination of an mGluR1 and an mGluR5 antagonist completely abolishes the 
plasticity [40]. A likely scenario is that both receptors cooperate to induce LTD. A less attractive alternative explanation would be that adaptations and strain differences confound the effects in $\mathrm{KO}$ mice. Conventional pharmacology studies on synapses outside the hippocampus suggest that either mGluR1 or mGluR5 activation mediates the LTD [33, 38, 39, 46, 48].

The postsynaptic induction mechanism of this form of LTD is confirmed by the requirement for elevated $\mathrm{Ca}^{2+}$ in some cases. The intracellular dialysis of $\mathrm{Ca}^{2+}$ chelators such as 1, 2-bis (aminophenoxy) ethane-N, N, N', N'-tetraacetic acid (BAPTA) blocks LTD under some conditions $[39,49]$ but seems inefficient in other reports $[50,51]$. Other postsynaptic manipulations, such as preventing the activation of the Ga subunit by the perfusion of guanosine 5'-O-(2-thiodiphosphate) (GDP $\beta S$ ) or disrupting tyrosine phosphorylation by loading the neurons with phosphatase inhibitors, also block the induction of mGluR-LTD $[48,52]$.

Gp I mGluRs couple to their effectors via G proteins of the Gq and G11 families, but LTD seems to depend mainly on the former. In the CA1 region of the hippocampus, DHPG fails to induce LTD in $\mathrm{Gq}^{-1-}$ mice, while the LTD is normal in $\mathrm{G} 11^{--}$mice [53]. Similarly, a paired-pulse stimulation protocol causes a regular LTD in G11 $1^{-1-}$ mice but a weak LTD in $\mathrm{Gq}^{-1-}$ mice [53]. Moreover, in the cerebellum, again only Gq ${ }^{-/}$seems to be necessary for mGluR-LTD [54].

Downstream of $\mathrm{G}$ proteins, mGluR1 and 5 activate the phospholipase $\mathrm{C}$ (PLC), resulting in an increase in inositol 1, 4, 5-trisphosphate (IP3) and diacylglycerol (DAG). IP3 and DAG then trigger $\mathrm{Ca}^{2+}$ release from the intracellular stores and activation of PKC. Direct evidence for the implication of PKC in mGluR-LTD has been found in several brain regions. In the CA1 region of the hippocampus, in cerebellar Purkinje cells, in sensory spinal synapses and in glutamatergic synapses onto dopaminergic neurons of the VTA, mGluR-LTD was abolished after loading the postsynaptic neuron with a PKC inhibitor $[39,55,56]$. Surprisingly, in the dentate gyrus, inhibition of PKA and PKC separately only decreased the magnitude of LTD; the combination of both drugs has yet to be tested [57]. The converging actions of PKA and PKC seem appealing, since the two of them activate the mitogen-activated protein kinase/extracellular signalregulated kinase (MAPK/ERK) pathway [58].

The following observations demonstrate the involvement of ERK in mGluR-LTD in different brain regions. In the CA1 region of the hippocampus, ERK inhibitors block LTD via a phosphorylation event [31, 40, 47, 59, 60]. Similarly, in the BNST, the plasticity was prevented by a specific antagonist of ERK and mGluR-LTD was no longer present in ERK $^{-1-}$ mice [48]. Similar results were obtained in the cerebellum [61, 62]. ERK inhibitors have been shown to block mGluR-LTD by preventing the internalization of GluR2-containing alpha-amino-3hydroxy-5-methyl-4-isoxazolepropionic acid receptors (AMPARs) [63]. In addition to ERK, Gp I mGluRs also activate the phosphoinsoitide 3-kinase (PI3K)-Akt-mammalian target of the rapamycin intracellular pathway (mTOR), as it occurs in the CA1 region of the hippocampus $[60,64]$. Finally, in the VTA mGluR-LTD only relies on mTOR activation [33].

Both ERK and mTOR are regulators of the translation machinery. Therefore Gp I mGluR-LTD may have a protein synthesis-dependent component, a hypothesis that is supported by several experimental studies [31, 47, 65]. Since polyribosomes can be observed in the proximity of synapses, protein synthesis may occur locally from prefabricated mRNA [66]. In fact, in the CA1 region of the hippocampus mGluR-LTD remained protein synthesis-dependent after dendrites were cut from the cell body, providing direct evidence for local translation [31]. Activation of mGluRs would therefore trigger an intracellular cascade, eventually activating ERK and/or mTOR, which would then turn on the protein synthesis machinery located in the dendrite. The final step would require translation of mRNAs into proteins that are essential for the persistence of the synaptic depression.

But which proteins need to be synthesized de novo? Appealing candidates are the AMPAR subunits themselves or immediate early genes that may regulate AMPA trafficking such as Arc [67, 68]. AMPAR subunits can be synthesized in dendrites upon DHPG application and in neuronal cultures; these subunits then form receptors that are synaptically inserted [69, 70]. Local mRNA translation definitely became the focus of attention after it was demonstrated that the mGluR-LTD in the hippocampus was enhanced in mutant mice lacking the fragile mental retardation protein (FMRP), the protein implicated in an Xlinked form of mental retardation [71]. Meanwhile, similar findings have been obtained in the cerebellum $[72,73]$. Since FMRP may act as a translational repressor [74], it was initially thought that the enhanced LTD in FMR1 ${ }^{-/-}$mice can be explained by a lack of inhibition of protein synthesis. Surprisingly, in FMR1 $1^{--}$mice mGluR-LTD is not only enhanced but also independent of ERK activity and protein synthesis [65, 72]. The precise role of FMRP is still under debate and may involve proteasome inhibition, where synthesis, ubiquitination and proteolysis of FMRP are part of a dynamic regulatory system that modulates mGluR-LTD in the hippocampus [65]. Further studies will have to identify the proteins that 
are the target of the protein synthesis machinery after mGluR activation.

In contrast, in the VTA [33] mGluR-LTD is mediatd by mTOR but independent of the FMRP (Mameli and Lüscher, unpublished data). When cells are loaded with siRNA and antisense oligonucleotides to specifically prevent GluR2 translation, mGluR-LTD is blocked within minutes [33]. This identifies the AMPAR GluR2 subunit as a protein that needs to be rapidly synthesized in order to express mGluRLTD.

Finally, during development the protein synthesis requirement for mGluR-LTD does not seem to be absolute. In fact, data obtained in acute brain slices prepared from 8 to 15 day-old mice demonstrate a developmental switch in the dependence of protein synthesis for mGluR-LTD in the hippocampus [75]. Whatever the exact nature of the proteins that need to be synthesized, there is a general consensus that Gp I mGluR-LTD is expressed by a redistribution of AMPARs. This process has first been described at a cerebellar synapse. Climbing fibers (CF) and parallel fibers that converge on Purkinje cells (PC) need to be activated together to depolarize the PC while activating mGluR1s. AMPARs are eventually internalized and the synaptic efficacy decreased. The activation of mGluR1 also triggers the retrograde release of endocannabinoids (eCB), which leads to the presynaptic depression of CF (see section below).

The expression mechanism of postsynaptic mGluR1LTD requires a redistribution of AMPARs via a kinase-dependent and a phosphatase-dependent cascade. The kinase activation cascade involves PLC/ DAG, activation of PKC and the phosphorylation of the GluR2 subunit at $\mathrm{Ser}^{880}$, leading to the internalization of the receptor. In parallel, nitric oxide activates cyclic guanosine monophosphate and cGMP-protein kinase, eventually suppressing dephosphorylation of the PKC target. The intracellular signal converges in the phosphorylation of GluR2, which promotes AMPAR internalization [76]. Electrophysiological approaches demonstrate that cerebellar mGluR-LTD requires a clathrin-dependent endocytosis [77]. In fact, a peptide that disrupts the interaction between dynamin and amphyphysin, which is required for receptor endocytosis [78], blocks mGluR-LTD in the hippocampus, cerebellum and VTA $[33,44]$.These findings are also supported by experiments with the actin stabilizer jasplakinolide, which also blocks synaptic removal of AMPARs and mGluR-LTD [44, 52]. The mechanism underlying the removal of AMPARs from the synapse has been shown to be associated with activation of postsynaptic protein tyrosine phosphatase, which leads to the tyrosine dephosphorylation of AMPARs and the subsequent internalization [52]. Moreover, immunocytochemical studies provide evidence for a decrease in the amount of postsynaptic GluR1 staining [44, 52, 57], an effect which is prevented by translation blockers [79]. Although a majority of observations demonstrate the important role of AMPAR internalization for the expression of mGluR-LTD, not all the data fit this model. The postsynaptic expression locus has been challenged, based on the observation that DHPG leads to the depression of synaptic currents but does not alter the amplitude of postsynaptic currents evoked by photolysis of caged glutamate [80]. However, this study is limited by the inability to distinguish between synaptic and extrasynaptic receptors after the glutamate uncaging, and can be reconciled with most of the findings discussed above, if mGluR-LTD also involves a lateral diffusion of AMPAR at the surface.

Several studies also suggest that mGluR-LTD can be expressed even if the total number of AMPA receptors does not change. mGluR-LTD in the VTA, for example, depends on the presence of GluR2-lacking receptors and it is expressed by rapid exchange of GluR2-lacking receptors for GluR2-containing ones $[32,33]$. These new GluR2-containing AMPARs have a lower conductance than GluR2-lacking AMPARs and this difference in channel properties is sufficient to explain the persistent decrease in synaptic strength without change in the number of receptors.

A puzzling feature of hippocampal mGluR-LTD is the requirement of a persistent activation of mGluRs throughout the expression phase. Several studies have shown that mGluR antagonists can reverse the plasticity even when applied long after induction [81, 82], while another study only observed a partial reversal [40].

In summary, Gp I mGluR-LTD is entirely postsynaptic, depends on rapid protein synthesis and involves a redistribution of AMPARs in all brain regions where it can be observed. The proteins that need to be synthesized and the regulation of the local translation as well as the exact composition of AMPARs in turn seem specific for a given brain region.

\section{Postsynaptic Gp II receptors}

In the cortex, mGluR-LTD can be induced through postsynaptic Gp II receptors [18]. For example, the bath application of the potent Gp II mGluRs agonist dicarboxycyclopropyl (DCG-IV) leads to a depression of excitatory synaptic currents in the rat prefrontal cortex. This form of plasticity requires the concomitant activation of mGluRs and dopamine receptors (D1 and D2), a rise in intracellular $\mathrm{Ca}^{2+}$ and the activation of PLC, PKC and MAP kinases [45, 83]. The LTD in the perirhinal cortex relies on the 
interaction between Gp II mGluRs, Gp I mGluRs and $\mathrm{N}$-methyl-D-aspartic acid receptors (NMDARs) [46]. A potential mechanism is that Gp II mGluRs amplify the rise in intracellular $\mathrm{Ca}^{2+}$ from intracellular stores triggered by Gp I mGluRs. The convergence of the two signals may occur via a synergistic interaction of the G $\beta \gamma$ subunits (Gp II mGluRs) and the Gq/11 subunits (Gp I mGluRs) [46]. At Schaffer collateral to CA1 synapses, low frequency stimulation induces a form of LTD that is dependent on the simultaneous activation of Gp II mGluRs and adenosine (A1) receptors. Both of these receptors are in fact negatively coupled to adenylate cyclase [41]. All these examples demonstrate the role of postsynaptic Gp II mGluR in the induction of LTD. However, little is known about the mechanism by which this plasticity is expressed. A study performed in the dentate gyrus in vivo reports that Gp II mGluR-LTD does not depend on protein synthesis [35]. Another possible explanation is that activation of mGluRs leads to a reduction of PKA levels, thereby promoting the dephosphorylation and endocytosis of AMPAR subunits [35].

In summary postsynaptic Gp II mGluRs can trigger a form of postsynaptically-expressed LTD in different areas of the cortex and hippopcampus.

\section{Postsynaptic induction - presynaptic expression}

This form of mGluR-LTD is induced by the activation of postsynaptic Gp I receptors, but has a presynaptic expression mechanism. It has long been known that the pharmacological activation of Gp I mGluRs leads to a LTD that is associated with an increase in paired pulse facilitation, reflecting a decrease of the presynaptic release probability $[84,85]$. Since Gp I mGluRs were exclusively found on the postsynaptic membrane $[36,86]$ a retrograde signal was postulated. Increasing evidence supports the idea that eCBs are synthesized from membrane-derived lipid precursors when an LTD induction protocol is applied. eCBs are then released from the dendrites of a depolarized neuron in a non-vescicular but $\mathrm{Ca}^{2+}$-dependent manner [87] and diffuse across the synaptic cleft to act through their receptors on afferent terminals, causing presynaptic inhibition and eventually LTD [88]. A rise in the postsynaptic $\mathrm{Ca}^{2+}$ concentration was essential in some experiments $[50,89,90]$, but this does not seem to be a universal requirement. Indeed, in the cerebellum and in the hippocampus, mGluRLTD can be elicited under conditions where $\mathrm{Ca}^{2+}$ is clamped in the presence of high concentrations of chelators [51, 91].

The release of eCB is facilitated when the depolarization is combined with mGluR activation, in which case the phospholipase C, beta 4 (PLCb4) could act as coincidence detector [92]. Concomitant depolarization and mild mGluR activation are able to induce eCB-depression, for example with agonist concentrations that normally are not effective [93]. eCB receptors, which can bind the marijuana constituent 89-tetrahydrocannabinol come in two subtypes: CB1 and $\mathrm{CB} 2$ receptors (CB1R and $\mathrm{CB} 2 \mathrm{R})$. While the CB2Rs are mainly found in the immune system, the CB1Rs are the target in central nervous system (CNS). Regions that express CB1Rs include the cerebellum, hippocampus, amygdala, basal ganglia, olfactory bulb, cerebral cortex and brainstem nuclei [87]. Similar to other Gi/o coupled receptors, CB1 receptor activation decreases the probability of transmitter release [94]. In slices of many brain regions, such retrograde signaling can be observed by the transient depression of either inhibitory or excitatory synaptic current when the postsynaptic cell is briefly depolarized [95-99]. While such depolarization-induced suppression of inhibition (DSI) or excitation (DSE) only last for a few tenths of seconds, it has been observed that sustained release of eCB might eventually lead to LTD; the activation of the postsynaptic Gq-coupled mGluRs is a way to trigger release of eCBs [100]. In fact eCB-LTD has been described in hippocampal neurons [91, 100], at excitatory synapse of the cerebellum, in the VTA $[89,101]$, at cortical efferences of the nucleus accumbens [90] and at inhibitory cerebellar synapses as well [102].

The induction requirements for long-lasting eCBmediated depression of synaptic transmission have been well described in PC of adult mice, where eCBLTD occurs along with mGluR1-LTD (Fig. 2). mGluR1 s are abundant in PCs [103] and in addition to triggering the internalization of AMPARs, they also lead to a decrease of neurotransmitter release, both from CF and parallel fibers (PF) via eCB release [101, 104]. Safo and Regehr have shown that induction of cerebellar LTD was eCB-dependent [104]. Indeed, LTD was lost in the presence of a CB1R antagonist and in CB1R KO mice. However much evidence indicates that cerebellar LTD is expressed postsynaptically.

It has been hypothesized that eCB signaling may have a role in regulating the temporal interaction between CF and PF to induce LTD [87]. Association of PF and CF activation makes the cerebellar LTD well suited to implement motor learning [105]. CF activity could provide a feedback to PF synapses and this would be important for fine motor control [106].

The role of eCB in hippocampal LTD is less clear. While one group observed only a transient effect after mGluR activation [82], others concluded that there are long-lasting presynaptic effects [80]. 


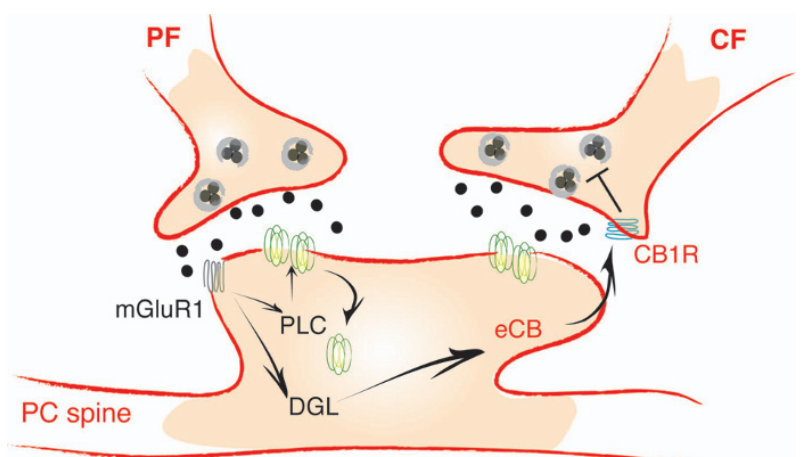

Figure 2. Model of mGluR-LTD in Purkinje cells (PC). PCs receive parallel fibers (PF) as well as climbing fibers (CF). Concomitant release from both afferents leads to mGluR1 and AMPARs activation. This leads to AMPAR-internalization via PKC activation at PF-PC synapses. At the same time, eCBs are released that decrease neurotransmitter release via $\mathrm{CB} 1 \mathrm{Rs}$ located at the $\mathrm{CF}$ terminal. Abbreviations: CB1R, cannabinoid receptor type 1; CF, climbing fibers; DGL, diacylglycerol lipase, eCB, endocannabinoids; PLC, phospholipase; PF, parallel fibers.

eCBs can also induce LTD at inhibitory synapses of the hippocampus, a phenomenon that is sometimes referred to as I-LTD. Simultaneous activation of Gp I mGluRs, mainly mGluR5, and postsynaptic depolarization lead to the release of eCBs and reduced transmitter release [91] that is long-lasting [107]. A similar form has been found in the amygdala where the activation of mGluR1 is both necessary and sufficient to induce the depression [108]. In contrast to the hippocampus, I-LTD in the amygdala is mediated by mGuR1 and by an eCB that is different from 2-Arachidonoylglycerol [87].

The basal ganglia are another part of the brain where eCB-LTD plays an important role. At cortico-striatal synapses a form of LTD that requires release of $\mathrm{eCB}$ from medium spiny neurons has been described [109]. Gp I mGluRs contribute to eCB-mediated short-term suppression of cortico-striatal excitatory synaptic transmission, but strong depolarization alone is not sufficient to trigger eCB release. In the dorsal striatum eCB-LTD is induced by the combined activation of mGluRs and L-type $\mathrm{Ca}^{2+}$ channels [110, 111]. In the nucleus accumbens, the induction of eCB-LTD requires the activation of mGluR5s on medium spiny neurons [112]. Interestingly this form of eCB-LTD is blocked by the repetitive exposure to an addictive drug such as cocaine [90].

The expression mechanism of I-LTD relies on changes in the transmitter release machinery mediated by cAMP/PKA signaling and the active zone protein RIM1 $\alpha$ [113]. It remains elusive whether this applies to eCB-LTD, as described above.

Interestingly, intense periods of synaptic activity at $\mathrm{CF}$ and $\mathrm{PF}$ inputs can also lead to an upregulation of glutamate transporters, resulting in a reduction of glutamate spill-out at the synaptic cleft. This, in turn, decreases mGluR-mediated $\mathrm{Ca}^{2+}$ signals and ultimately mGluR-LTD. Conversely, when transporters are sparse, the induction of LTD is facilitated [114]. In summary, postsynaptic Gp I mGluRs in neurons in almost all regions of the brain can trigger the synthesis of eCBs, which act as retrograde messengers to decrease presynaptic release probability. At some synapses, sustained CB1 activation may lead to permanent depression of synaptic transmission.

\section{LTD of the slow EPSC}

Synaptically released glutamate can produce a slow excitatory current via activation of mGluRs (slow EPSC) in addition to the fast EPSCs. Recent work now shows that the slow mGluR-mediated EPSC can undergo LTD (LTD (mGluR1)) [115].

In the cerebellum for example, the slow EPSC depends on the cation channel TRPC1 [116], which is triggered by intracellular $\mathrm{Ca}^{2+}$ downstream of mGluR1. The induction of LTD (mGluR1) requires very strong CF-induced PC depolarization stimulation [115], the PF-evoked slow EPSC. LTD of the slow EPSC is also observed when slow synaptic current is evoked by exogenous application of an mGluR1 agonist, suggesting that LTD is expressed via a postsynaptic mechanism. The authors propose that LTD (mGluR1) is expressed postsynaptically by the attenuation of an initial step of the signaling complex, where the ultimate target could be the mGluR1 itself, Gaq or an annexed scaffolding protein [115].

How is this form of plasticity expressed? Little is known about the trafficking of mGluRs. In recombinant systems, the activation of mGluRs with glutamate for long periods of time led to the internalization of the receptors to endosomes, a mechanism that depends on arrestin and dynamin [117]. In this system, the surface expression of mGluRs can be rapidly regulated in response to agonist activation [118]. Moreover it seems that strong depolarization induced by $\mathrm{KCl}$ in cultured Purkinje neurons can also increase mGluR1 immunoreactivity [119, 120]. These data highlight the potential role of mGluRs in modulating their own activity. In fact, LTD (mGluR1) blocked the subsequent induction of conventional mGluR-LTD of AMPAR-mediated signals [115], suggesting that LTD (mGluR1) plays a role in forms of metaplasticity.

\section{Conclusions}

In this review we compiled brain regions where mGluR-LTD was observed and we categorized differ- 
ent forms by their locus of induction and expression (Table 1, Fig. 1). We have not considered differences due to developmental stages that can add complexity $[52,75,80]$. Although we have covered a large part of the available literature, the list may not be exhaustive, and it is probable that future studies will uncover new forms of mGluR-LTD in parts of the brain not yet investigated. Such considerations should be kept in mind when discussing inconsistencies in available literature.

In conclusion, the functions of mGluRs in synaptic plasticity are manifold and range from organizing receptor redistribution, release of retrograde messengers to autoregulation of mGluR-signaling and a modulation of other forms of long-term plasticity. mGluRs may therefore be key determinants of many brain functions in health and disease.

1 Bear, M. F. and Abraham, W. C. (1996) Long-term depression in hippocampus. Annu. Rev. Neurosci. 19, 437-462.

2 Bear, M. F. and Malenka, R. C. (1994) Synaptic plasticity: LTP and LTD. Curr. Opin. Neurobiol. 4, 389-399.

3 Bortolotto, Z. A., Fitzjohn, S. M. and Collingridge, G. L. (1999) Roles of metabotropic glutamate receptors in LTP and LTD in the hippocampus. Curr. Opin. Neurobiol. 9, 299-304.

4 Conn, P. J. and Pin, J. P. (1997) Pharmacology and functions of metabotropic glutamate receptors. Annu. Rev. Pharmacol. Toxicol. 37, 205-237.

5 Anwyl, R. (1999) Metabotropic glutamate receptors: electrophysiological properties and role in plasticity. Brain Res. Brain Res. Rev. 29, 83-120.

6 Pin, J. P. and Acher, F. (2002) The metabotropic glutamate receptors: structure, activation mechanism and pharmacology. Curr. Drug Targets CNS Neurol. Disord. 1, 297-317.

7 Knoflach, F. and Kemp, J. A. (1998) Metabotropic glutamate group II receptors activate a $G$ protein-coupled inwardly rectifying $\mathrm{K}+$ current in neurones of the rat cerebellum. J. Physiol. 509, 347-354.

8 Schoepp, D. D. (2001) Unveiling the functions of presynaptic metabotropic glutamate receptors in the central nervous system. J. Pharmacol. Exp. Ther. 299, 12-20.

9 Giustizieri, M., Bernardi, G., Mercuri, N. B. and Berretta, N. (2005) Distinct mechanisms of presynaptic inhibition at GABAergic synapses of the rat substantia nigra pars compacta. J. Neurophysiol. 94, 1992-2003.

10 von Gersdorff, H., Schneggenburger, R., Weis, S. and Neher, E. (1997) Presynaptic depression at a calyx synapse: the small contribution of metabotropic glutamate receptors. J. Neurosci. $17,8137-8146$.

11 Lujan, R., Roberts, J. D., Shigemoto, R., Ohishi, H. and Somogyi, P. (1997) Differential plasma membrane distribution of metabotropic glutamate receptors mGluR1 alpha, mGluR2 and mGluR5, relative to neurotransmitter release sites. J. Chem. Neuroanat. 13, 219-241.

12 Shigemoto, R., Kinoshita, A., Wada, E., Nomura, S., Ohishi, H., Takada, M., Flor, P. J., Neki, A., Abe, T., Nakanishi, S. and Mizuno, N. (1997) Differential presynaptic localization of metabotropic glutamate receptor subtypes in the rat hippocampus. J. Neurosci. 17, 7503-7522.

13 Mateos, J. M., Elezgarai, I., Benitez, R., Osorio, A., Bilbao, A., Azkue, J. J., Kuhn, R., Knopfel, T. and Grandes, P. (1999) Clustering of the group III metabotropic glutamate receptor 4a at parallel fiber synaptic terminals in the rat cerebellar molecular layer. Neurosci. Res. 35, 71-74.

14 Corti, C., Aldegheri, L., Somogyi, P. and Ferraguti, F. (2002) Distribution and synaptic localisation of the metabotropic glutamate receptor 4 (mGluR4) in the rodent CNS. Neuroscience 110, 403-420.

15 Acsady, L., Kamondi, A., Sik, A., Freund, T. and Buzsaki, G. (1998) GABAergic cells are the major postsynaptic targets of mossy fibers in the rat hippocampus. J. Neurosci. 18, 33863403.

16 Tzounopoulos, T., Janz, R., Sudhof, T. C., Nicoll, R. A. and Malenka, R. C. (1998) A role for cAMP in long-term depression at hippocampal mossy fiber synapses. Neuron 21, 837-845.

17 Scanziani, M., Salin, P. A., Vogt, K. E., Malenka, R. C. and Nicoll, R. A. (1997) Use-dependent increases in glutamate concentration activate presynaptic metabotropic glutamate receptors. Nature 385, 630-634.

18 Petralia, R. S., Wang, Y. X., Niedzielski, A. S. and Wenthold, R. J. (1996) The metabotropic glutamate receptors, mGluR2 and mGluR3, show unique postsynaptic, presynaptic and glial localizations. Neuroscience 71, 949-976.

19 Kobayashi, K., Manabe, T. and Takahashi, T. (1996) Presynaptic long-term depression at the hippocampal mossy fiberCA3 synapse. Science 273, 648-650.

20 Yokoi, M., Kobayashi, K., Manabe, T., Takahashi, T., Sakaguchi, I., Katsuura, G., Shigemoto, R., Ohishi, H., Nomura, S., Nakamura, K., Nakao, K., Katsuki, M. and Nakanishi, S. (1996) Impairment of hippocampal mossy fiber LTD in mice lacking mGluR2. Science 273, 645-647.

21 Pelkey, K. A., Lavezzari, G., Racca, C., Roche, K. W. and McBain, C. J. (2005) mGluR7 is a metaplastic switch controlling bidirectional plasticity of feedforward inhibition. Neuron $46,89-102$.

22 Ayala, J. E., Niswender, C. M., Luo, Q., Banko, J. L. and Conn, P. J. (2007) Group III mGluR regulation of synaptic transmission at the SC-CA1 synapse is developmentally regulated. Neuropharmacology 54, 804-14.

23 Swartz, K. J., Merritt, A., Bean, B. P. and Lovinger, D. M. (1993) Protein kinase C modulates glutamate receptor inhibition of $\mathrm{Ca} 2+$ channels and synaptic transmission. Nature 361, 165-168.

24 Kamiya, H. and Yamamoto, C. (1997) Phorbol ester and forskolin suppress the presynaptic inhibitory action of groupII metabotropic glutamate receptor at rat hippocampal mossy fibre synapse. Neuroscience 80, 89-94.

25 Macek, T. A., Schaffhauser, H. and Conn, P. J. (1998) Protein kinase $\mathrm{C}$ and $\mathrm{A} 3$ adenosine receptor activation inhibit presynaptic metabotropic glutamate receptor (mGluR) function and uncouple mGluRs from GTP-binding proteins. J. Neurosci. 18, 6138-6146.

26 Schaffhauser, H., Cai, Z., Hubalek, F., Macek, T. A., Pohl, J., Murphy, T. J. and Conn, P. J. (2000) cAMP-dependent protein kinase inhibits mGluR2 coupling to G-proteins by direct receptor phosphorylation. J. Neurosci. 20, 5663-5670.

27 Mateo, Z. and Porter, J. T. (2007) Group II metabotropic glutamate receptors inhibit glutamate release at thalamocortical synapses in the developing somatosensory cortex. Neuroscience 146, 1062-1072.

28 Lin, H. C., Wang, S. J., Luo, M. Z. and Gean, P. W. (2000) Activation of group II metabotropic glutamate receptors induces long-term depression of synaptic transmission in the rat amygdala. J. Neurosci. 20, 9017-9024.

29 Chen, C. Y., Ling Eh, E. H., Horowitz, J. M. and Bonham, A. C. (2002) Synaptic transmission in nucleus tractus solitarius is depressed by Group II and III but not Group I presynaptic metabotropic glutamate receptors in rats. J. Physiol. 538, $773-$ 786.

30 Neale, S. A., Garthwaite, J. and Batchelor, A. M. (2001) Metabotropic glutamate receptor subtypes modulating neurotransmission at parallel fibre-Purkinje cell synapses in rat cerebellum. Neuropharmacology 41, 42-49.

31 Huber, K. M., Kayser, M. S. and Bear, M. F. (2000) Role for rapid dendritic protein synthesis in hippocampal mGluRdependent long-term depression. Science 288, 1254-1257. 
32 Bellone, C. and Luscher, C. (2006) Cocaine triggered AMPA receptor redistribution is reversed in vivo by $\mathrm{mGluR}$-dependent long-term depression. Nat. Neurosci. 9, 636-641.

33 Mameli, M., Balland, B., Lujan, R. and Luscher, C. (2007) Rapid synthesis and synaptic insertion of GluR2 for mGluRLTD in the ventral tegmental area. Science 317, 530-533.

34 Grueter, B. A. and Winder, D. G. (2005) Group II and III metabotropic glutamate receptors suppress excitatory synaptic transmission in the dorsolateral bed nucleus of the stria terminalis. Neuropsychopharmacology 30, 1302-1311.

35 Poschel, B. and Manahan-Vaughan, D. (2005) Group II mGluR-induced long term depression in the dentate gyrus in vivo is NMDA receptor-independent and does not require protein synthesis. Neuropharmacology 49 Suppl. 1, 1-12.

36 Lujan, R., Nusser, Z., Roberts, J. D., Shigemoto, R. and Somogyi, P. (1996) Perisynaptic location of metabotropic glutamate receptors mGluR1 and mGluR5 on dendrites and dendritic spines in the rat hippocampus. Eur. J. Neurosci. 8, $1488-1500$.

37 Lopez-Bendito, G., Shigemoto, R., Fairen, A. and Lujan, R. (2002) Differential distribution of group I metabotropic glutamate receptors during rat cortical development. Cereb. Cortex 12, 625-638.

38 Harney, S. C., Rowan, M. and Anwyl, R. (2006) Long-term depression of NMDA receptor-mediated synaptic transmission is dependent on activation of metabotropic glutamate receptors and is altered to long-term potentiation by low intracellular calcium buffering. J. Neurosci. 26, 1128-1132.

39 Bellone, C. and Luscher, C. (2005) mGluRs induce a longterm depression in the ventral tegmental area that involves a switch of the subunit composition of AMPA receptors. Eur. J. Neurosci. 21, 1280-1288.

40 Volk, L. J., Daly, C. A. and Huber, K. M. (2006) Differential roles for group $1 \mathrm{mGluR}$ subtypes in induction and expression of chemically induced hippocampal long-term depression. J. Neurophysiol. 95, 2427-2438.

41 Santschi, L. A., Zhang, X. L. and Stanton, P. K. (2006) Activation of receptors negatively coupled to adenylate cyclase is required for induction of long-term synaptic depression at Schaffer collateral-CA1 synapses. J. Neurobiol. 66, 205-219.

42 Cho, K. and Bashir, Z. I. (2002) Cooperation between mglu receptors: a depressing mechanism? Trends Neurosci. 25, $405-411$.

43 Ueta, Y., Yamamoto, R., Sugiura, S., Inokuchi, K. and Kato, N. (2008) Homer 1a suppresses neocortex long-term depression in a cortical layer-specific manner. J. Neurophysiol. 99, 950-957.

44 Xiao, M. Y., Zhou, Q. and Nicoll, R. A. (2001) Metabotropic glutamate receptor activation causes a rapid redistribution of AMPA receptors. Neuropharmacology 41, 664-671.

45 Otani, S., Auclair, N., Desce, J. M., Roisin, M. P. and Crepel, F. (1999) Dopamine receptors and groups I and II mGluRs cooperate for long-term depression induction in rat prefrontal cortex through converging postsynaptic activation of MAP kinases. J. Neurosci. 19, 9788-9802.

46 Cho, K., Kemp, N., Noel, J., Aggleton, J. P., Brown, M. W. and Bashir, Z. I. (2000) A new form of long-term depression in the perirhinal cortex. Nat. Neurosci. 3, 150-156.

47 Huber, K. M., Roder, J. C. and Bear, M. F. (2001) Chemical induction of mGluR5- and protein synthesis-dependent longterm depression in hippocampal area CA1. J. Neurophysiol. 86, 321-325.

48 Grueter, B. A., Gosnell, H. B., Olsen, C. M., SchrammSapyta, N. L., Nekrasova, T., Landreth, G. E. and Winder, D. G. (2006) Extracellular-signal regulated kinase 1-dependent metabotropic glutamate receptor 5-induced long-term depression in the bed nucleus of the stria terminalis is disrupted by cocaine administration. J. Neurosci. 26, 3210-3219.

49 Oliet, S. H., Malenka, R. C. and Nicoll, R. A. (1997) Two distinct forms of long-term depression coexist in CA1 hippocampal pyramidal cells. Neuron 18, 969-982.
50 Bolshakov, V. Y. and Siegelbaum, S. A. (1994) Postsynaptic induction and presynaptic expression of hippocampal longterm depression. Science 264, 1148-1152.

51 Fitzjohn, S. M., Palmer, M. J., May, J. E., Neeson, A., Morris, S. A. and Collingridge, G. L. (2001) A characterisation of longterm depression induced by metabotropic glutamate receptor activation in the rat hippocampus in vitro. J. Physiol. 537, 421 430.

52 Moult, P. R., Gladding, C. M., Sanderson, T. M., Fitzjohn, S. M., Bashir, Z. I., Molnar, E. and Collingridge, G. L. (2006) Tyrosine phosphatases regulate AMPA receptor trafficking during metabotropic glutamate receptor-mediated long-term depression. J. Neurosci. 26, 2544-2554.

53 Kleppisch, T., Voigt, V., Allmann, R. and Offermanns, S. (2001) G(alpha)q-deficient mice lack metabotropic glutamate receptor-dependent long-term depression but show normal long-term potentiation in the hippocampal CA1 region. J. Neurosci. 21, 4943-4948.

54 Hartmann, J., Blum, R., Kovalchuk, Y., Adelsberger, H., Kuner, R., Durand, G. M., Miyata, M., Kano, M., Offermanns, S. and Konnerth, A. (2004) Distinct roles of Galpha(q) and Galpha11 for Purkinje cell signaling and motor behavior. J. Neurosci. 24, 5119-5130.

55 Linden, D. J. and Connor, J. A. (1991) Participation of postsynaptic PKC in cerebellar long-term depression in culture. Science 254, 1656-1659.

56 Heinke, B. and Sandkuhler, J. (2005) Signal transduction pathways of group I metabotropic glutamate receptor-induced long-term depression at sensory spinal synapses. Pain $118,145-154$

57 Huang, L. Q., Rowan, M. J. and Anwyl, R. (1999) Role of protein kinases $\mathrm{A}$ and $\mathrm{C}$ in the induction of mGluR-dependent long-term depression in the medial perforant path of the rat dentate gyrus in vitro. Neurosci. Lett. 274, 71-74.

58 Adams, J. P. and Sweatt, J. D. (2002) Molecular psychology: roles for the ERK MAP kinase cascade in memory. Annu. Rev. Pharmacol. Toxicol. 42, 135-163.

59 Ronesi, J. A. and Huber, K. M. (2008) Homer interactions are necessary for metabotropic glutamate receptor-induced longterm depression and translational activation. J. Neurosci. 28, 543-547.

60 Gallagher, S. M., Daly, C. A., Bear, M. F. and Huber, K. M. (2004) Extracellular signal-regulated protein kinase activation is required for metabotropic glutamate receptor-dependent long-term depression in hippocampal area CA1. J. Neurosci. 24, 4859-4864.

61 Kawasaki, H., Fujii, H., Gotoh, Y., Morooka, T., Shimohama, S., Nishida, E. and Hirano, T. (1999) Requirement for mitogen-activated protein kinase in cerebellar long term depression. J. Biol. Chem. 274, 13498-13502.

62 Ahn, S., Ginty, D. D. and Linden, D. J. (1999) A late phase of cerebellar long-term depression requires activation of CaMKIV and CREB. Neuron 23, 559-568.

63 Endo, S. and Launey, T. (2003) ERKs regulate PKC-dependent synaptic depression and declustering of glutamate receptors in cerebellar Purkinje cells. Neuropharmacology 45, 863872.

64 Hou, L. and Klann, E. (2004) Activation of the phosphoinositide 3-kinase-Akt-mammalian target of rapamycin signaling pathway is required for metabotropic glutamate receptordependent long-term depression. J. Neurosci. 24, 6352-6361.

65 Hou, L., Antion, M. D., Hu, D., Spencer, C. M., Paylor, R. and Klann, E. (2006) Dynamic translational and proteasomal regulation of fragile $\mathrm{X}$ mental retardation protein controls mGluR-dependent long-term depression. Neuron 51, 441454.

66 Steward, O., Falk, P. M. and Torre, E. R. (1996) Ultrastructural basis for gene expression at the synapse: synapseassociated polyribosome complexes. J. Neurocytol. 25, 717734.

67 Chowdhury, S., Shepherd, J. D., Okuno, H., Lyford, G., Petralia, R. S., Plath, N., Kuhl, D., Huganir, R. L. and Worley, 
P. F. (2006) Arc/Arg3.1 interacts with the endocytic machinery to regulate AMPA receptor trafficking. Neuron 52, 445-459.

68 Tzingounis, A. V. and Nicoll, R. A. (2006) Arc/Arg3.1: linking gene expression to synaptic plasticity and memory. Neuron 52, 403-407.

$69 \mathrm{Ju}$, W., Morishita, W., Tsui, J., Gaietta, G., Deerinck, T. J., Adams, S. R., Garner, C. C., Tsien, R. Y., Ellisman, M. H. and Malenka, R. C. (2004) Activity-dependent regulation of dendritic synthesis and trafficking of AMPA receptors. Nat. Neurosci. 7, 244-253.

70 Kacharmina, J. E., Job, C., Crino, P. and Eberwine, J. (2000) Stimulation of glutamate receptor protein synthesis and membrane insertion within isolated neuronal dendrites. Proc. Natl. Acad. Sci. USA 97, 11545-11550.

71 Dolen, G. and Bear, M. F. (2008) Role for metabotropic glutamate receptor 5 (mGluR5) in the pathogenesis of fragile X syndrome. J. Physiol. 586, 1503-1508.

72 Huber, K. M., Gallagher, S. M., Warren, S. T. and Bear, M. F. (2002) Altered synaptic plasticity in a mouse model of fragile X mental retardation. Proc. Natl. Acad. Sci. USA 99, $7746-$ 7750.

73 Koekkoek, S. K., Yamaguchi, K., Milojkovic, B. A., Dortland B. R., Ruigrok, T. J., Maex, R., De Graaf, W., Smit, A. E., VanderWerf, F., Bakker, C. E., Willemsen, R., Ikeda, T., Kakizawa, S., Onodera, K., Nelson, D. L., Mientjes, E., Joosten, M., De Schutter, E., Oostra, B. A., Ito, M. and De Zeeuw, C. I. (2005) Deletion of FMR1 in Purkinje cells enhances parallel fiber LTD, enlarges spines, and attenuates cerebellar eyelid conditioning in Fragile X syndrome. Neuron 47, 339-352.

74 Zhang, Y. Q., Bailey, A. M., Matthies, H. J., Renden, R. B., Smith, M. A., Speese, S. D., Rubin, G. M. and Broadie, K. (2001) Drosophila fragile X-related gene regulates the MAP1B homolog Futsch to control synaptic structure and function. Cell 107, 591-603.

75 Nosyreva, E. D. and Huber, K. M. (2005) Developmental switch in synaptic mechanisms of hippocampal metabotropic glutamate receptor-dependent long-term depression. J. Neurosci. $25,2992-3001$.

76 Evans, G. J. (2007) Synaptic signalling in cerebellar plasticity. Biol. Cell 99, 363-378.

77 Wang, Y. T. and Linden, D. J. (2000) Expression of cerebellar long-term depression requires postsynaptic clathrin-mediated endocytosis. Neuron 25, 635-647.

78 Luscher, C., Xia, H., Beattie, E. C., Carroll, R. C., von Zastrow, M., Malenka, R. C. and Nicoll, R. A. (1999) Role of AMPA receptor cycling in synaptic transmission and plasticity. Neuron 24, 649-658.

79 Snyder, E. M., Philpot, B. D., Huber, K. M., Dong, X., Fallon, J. R. and Bear, M. F. (2001) Internalization of ionotropic glutamate receptors in response to mGluR activation. Nat. Neurosci. 4, 1079-1085.

80 Rammes, G., Palmer, M., Eder, M., Dodt, H. U., Zieglgansberger, W. and Collingridge, G. L. (2003) Activation of mGlu receptors induces LTD without affecting postsynaptic sensitivity of CA1 neurons in rat hippocampal slices. J. Physiol. 546, 455-460.

81 Fitzjohn, S. M., Kingston, A. E., Lodge, D. and Collingridge, G. L. (1999) DHPG-induced LTD in area CA1 of juvenile rat hippocampus; characterisation and sensitivity to novel mGlu receptor antagonists. Neuropharmacology 38, 1577-1583.

82 Rouach, N. and Nicoll, R. A. (2003) Endocannabinoids contribute to short-term but not long-term mGluR-induced depression in the hippocampus. Eur. J. Neurosci. 18, $1017-$ 1020.

83 Otani, S., Daniel, H., Takita, M. and Crepel, F. (2002) Longterm depression induced by postsynaptic group II metabotropic glutamate receptors linked to phospholipase $\mathrm{C}$ and intracellular calcium rises in rat prefrontal cortex. J. Neurosci. 22, 3434-3444.

84 Watabe, A. M., Carlisle, H. J. and O'Dell, T. J. (2002) Postsynaptic induction and presynaptic expression of group 1
mGluR-dependent LTD in the hippocampal CA1 region. J. Neurophysiol. 87, 1395-1403.

85 Faas, G. C., Adwanikar, H., Gereau, R. W.t. and Saggau, P. (2002) Modulation of presynaptic calcium transients by metabotropic glutamate receptor activation: a differential role in acute depression of synaptic transmission and longterm depression. J. Neurosci. 22, 6885-6890.

86 Baude, A., Nusser, Z., Roberts, J. D., Mulvihill, E., McIlhinney, R. A. and Somogyi, P. (1993) The metabotropic glutamate receptor (mGluR1 alpha) is concentrated at perisynaptic membrane of neuronal subpopulations as detected by immunogold reaction. Neuron 11, 771-787.

87 Chevaleyre, V., Takahashi, K. A. and Castillo, P. E. (2006) Endocannabinoid-mediated synaptic plasticity in the CNS. Annu. Rev. Neurosci. 29, 37-76.

88 Kreitzer, A. C. (2005) Neurotransmission: emerging roles of endocannabinoids. Curr. Biol. 15, R549-51.

89 Melis, M., Pistis, M., Perra, S., Muntoni, A. L., Pillolla, G. and Gessa, G. L. (2004) Endocannabinoids mediate presynaptic inhibition of glutamatergic transmission in rat ventral tegmental area dopamine neurons through activation of CB1 receptors. J. Neurosci 24, 53-62.

90 Fourgeaud, L., Mato, S., Bouchet, D., Hemar, A., Worley, P. F. and Manzoni, O. J. (2004) A single in vivo exposure to cocaine abolishes endocannabinoid-mediated long-term depression in the nucleus accumbens. J. Neurosci. 24, 6939-6945.

91 Ohno-Shosaku, T.,., Shosaku, J., Tsubokawa, H. and Kano, M. (2002) Cooperative endocannabinoid production by neuronal depolarization and group I metabotropic glutamate receptor activation. Eur. J. Neurosci. 15, 953-961.

92 Maejima, T., Oka, S., Hashimotodani, Y., Ohno-Shosaku, T., Aiba, A., Wu, D., Waku, K., Sugiura, T. and Kano, M. (2005) Synaptically driven endocannabinoid release requires $\mathrm{Ca} 2+-$ assisted metabotropic glutamate receptor subtype 1 to phospholipase Cbeta4 signaling cascade in the cerebellum. J. Neurosci. 25, 6826-6835.

93 Hashimotodani, Y., Ohno-Shosaku, T., Tsubokawa, H., Ogata, H., Emoto, K., Maejima, T., Araishi, K., Shin, H. S. and Kano, M. (2005) Phospholipase Cbeta serves as a coincidence detector through its $\mathrm{Ca} 2+$ dependency for triggering retrograde endocannabinoid signal. Neuron 45, 257-268.

94 Alger, B. E. (2002) Retrograde signaling in the regulation of synaptic transmission: focus on endocannabinoids. Prog. Neurobiol. 68, 247-286.

95 Wilson, R. I. and Nicoll, R. A. (2001) Endogenous cannabinoids mediate retrograde signalling at hippocampal synapses. Nature 410, 588-592.

96 Kreitzer, A. C. and Regehr, W. G. (2001) Retrograde inhibition of presynaptic calcium influx by endogenous cannabinoids at excitatory synapses onto Purkinje cells. Neuron 29, 717-727.

97 Trettel, J. and Levine, E. S. (2003) Endocannabinoids mediate rapid retrograde signaling at interneuron right-arrow pyramidal neuron synapses of the neocortex. J. Neurophysiol. 89, 2334-2338.

98 Yanovsky, Y., Mades, S. and Misgeld, U. (2003) Retrograde signaling changes the venue of postsynaptic inhibition in rat substantia nigra. Neuroscience 122, 317-328.

99 Melis, M., Perra, S., Muntoni, A. L., Pillolla, G., Lutz, B., Marsicano, G., Di Marzo, V., Gessa, G. L. and Pistis, M. (2004) Prefrontal cortex stimulation induces 2-arachidonoyl-glycerol-mediated suppression of excitation in dopamine neurons. J. Neurosci. 24, 10707-10715.

100 Varma, N., Carlson, G. C., Ledent, C. and Alger, B. E. (2001) Metabotropic glutamate receptors drive the endocannabinoid system in hippocampus. J. Neurosci. 21, RC188.

101 Maejima, T., Hashimoto, K., Yoshida, T., Aiba, A. and Kano, M. (2001) Presynaptic inhibition caused by retrograde signal from metabotropic glutamate to cannabinoid receptors. Neuron 31, 463-475. 
102 Galante, M. and Diana, M. A. (2004) Group I metabotropic glutamate receptors inhibit GABA release at interneuronPurkinje cell synapses through endocannabinoid production. J. Neurosci. 24, 4865-4874.

103 Nusser, Z., Mulvihill, E., Streit, P. and Somogyi, P. (1994) Subsynaptic segregation of metabotropic and ionotropic glutamate receptors as revealed by immunogold localization. Neuroscience 61, 421-427.

104 Safo, P. K. and Regehr, W. G. (2005) Endocannabinoids control the induction of cerebellar LTD. Neuron 48, 647-659.

105 Ito, M. (2001) Cerebellar long-term depression: characterization, signal transduction, and functional roles. Physiol. Rev. 81, 1143-1195.

106 Brenowitz, S. D. and Regehr, W. G. (2005) Associative shortterm synaptic plasticity mediated by endocannabinoids Neuron 45, 419-431.

107 Chevaleyre, V. and Castillo, P. E. (2003) Heterosynaptic LTD of hippocampal GABAergic synapses: a novel role of endocannabinoids in regulating excitability. Neuron 38 , $461-472$.

108 Azad, S. C., Monory, K., Marsicano, G., Cravatt, B. F., Lutz, B., Zieglgansberger, W. and Rammes, G. (2004) Circuitry for associative plasticity in the amygdala involves endocannabinoid signaling. J. Neurosci. 24, 9953-9961.

109 Gerdeman, G. L., Ronesi, J. and Lovinger, D. M. (2002) Postsynaptic endocannabinoid release is critical to long-term depression in the striatum. Nat. Neurosci. 5, 446-451.

110 Kreitzer, A. C. and Malenka, R. C. (2005) Dopamine modulation of state-dependent endocannabinoid release and long-term depression in the striatum. J. Neurosci. 25, $10537-10545$.

111 Narushima, M., Hashimoto, K. and Kano, M. (2006) Endocannabinoid-mediated short-term suppression of excitatory synaptic transmission to medium spiny neurons in the striatum. Neurosci. Res. 54, 159-164.
112 Robbe, D., Kopf, M., Remaury, A., Bockaert, J. and Manzoni, O. J. (2002) Endogenous cannabinoids mediate long-term synaptic depression in the nucleus accumbens. Proc. Natl. Acad. Sci. USA 99, 8384-8388.

113 Chevaleyre, V., Heifets, B. D., Kaeser, P. S., Sudhof, T. C. and Castillo, P. E. (2007) Endocannabinoid-mediated long-term plasticity requires cAMP/PKA signaling and RIM1alpha. Neuron 54, 801-812.

114 Wadiche, J. I. and Jahr, C. E. (2005) Patterned expression of Purkinje cell glutamate transporters controls synaptic plasticity. Nat. Neurosci. 8, 1329-1334.

115 Jin, Y., Kim, S. J., Kim, J., Worley, P. F. and Linden, D. J. (2007) Long-term depression of mGluR1 signaling. Neuron 55, 277287.

116 Kim, S. J., Kim, Y. S., Yuan, J. P., Petralia, R. S., Worley, P. F. and Linden, D. J. (2003) Activation of the TRPC1 cation channel by metabotropic glutamate receptor mGluR1. Nature 426, 285-291.

117 Mundell, S. J., Matharu, A. L., Pula, G., Roberts, P. J. and Kelly, E. (2001) Agonist-induced internalization of the metabotropic glutamate receptor $1 \mathrm{a}$ is arrestin- and dynamin-dependent. J. Neurochem. 78, 546-551.

118 Doherty, A. J., Coutinho, V., Collingridge, G. L. and Henley, J. M. (1999) Rapid internalization and surface expression of a functional, fluorescently tagged G-protein-coupled glutamate receptor. Biochem. J. 341, 415-422.

119 Minami, I., Kengaku, M., Smitt, P. S., Shigemoto, R. and Hirano, T. (2003) Long-term potentiation of mGluR1 activity by depolarization-induced Homer1a in mouse cerebellar Purkinje neurons. Eur. J. Neurosci. 17, 1023-1032.

120 Kim, S. J. and Linden, D. J. (2007) Ubiquitous plasticity and memory storage. Neuron $56,582-592$.

\section{To access this journal online: http://www.birkhauser.ch/CMLS}

